\title{
CONTEXTO DA INTERNACIONALIZAÇÃO NA CONTEMPORANEIDADE: DESAFIOS E PERSPECTIVAS DA UNIVERSIDADE DO ESTADO DA BAHIA
}

\author{
Natanael Reis Bonfim (UNEB)* \\ https://orcid.org/0000-0002-5122-9820 \\ Gabriela Sousa Rêgo Pimentel (UNEB)** \\ https://orcid.org/0000-0002-4278-0573 \\ Mateus Santos Souza (UNEB)*** \\ https://orcid.org/0000-0001-5174-9407
}

\section{RESUMO}

O objetivo deste artigo é discutir sobre o desenvolvimento das ações de internacionalização na Educação Superior, nas últimas décadas. Apresenta as dimensões deste conceito como forma de apreender a política que intervém sobre as decisões educacionais e como ela pode adquirir significados diferentes, dependendo de quem está na fonte de sua "interpretação" e do contexto ao qual ela se aplica. No campo empírico, analisa o papel da Universidade do Estado da Bahia (UNEB) no contexto da contemporaneidade, a partir de suas ações de internacionalização. Trata-se de uma pesquisa exploratória e documental, cujos resultados apontam lacunas conceituais, evidenciam a necessidade de maiores investimentos em pesquisas que aprofundam o entendimento dos diversos aspectos concernentes à internacionalização e constatam os desafios enfrentados na UNEB para implementação de uma política institucional de internacionalização.

Palavras-chave: Política de internacionalização. Educação superior. Contemporaneidade.

Pós-Doutor em Educação e Turismo pela Universidade Sorbonne/Paris 1. PhD em Educação pela Universidade do Quebec em Montreal (UQAM). Secretário da Secretaria Especial de Relações Internacionais (SERINT/UNEB). Professor Permanente do Programa de Pós-Graduação em Educação e Contemporaneidade da Universidade do Estado da Bahia (PPGEduC/UNEB). Líder do Grupo Interdisciplinar de Pesquisa em Representações, Educação e Sustentabilidade (GIPRES/UNEB). E-mail: nabom_reis@hotmail.com

** Pós-Doutora em Educação pela Universidade Católica do Salvador (UCSal). Doutora em Educação pela Universidade Católica de Brasília (UCB), com ênfase em Políticas Públicas, Economia e Gestão da Educação. Professora Permanente do Programa de Pós-Graduação em Educação e Contemporaneidade da Universidade do Estado da Bahia (PPGEduC/UNEB). Líder do grupo de pesquisa Políticas Públicas e Gestão da Educação (EDUCATIO/UNEB). E-mail: meg.pimentel@uol.com.br

*** Mestrando em Educação pelo Programa de Pós-graduação em Educação e Contemporaneidade da Universidade do Estado da Bahia (PPGEduC/UNEB). Membro do Grupo Interdisciplinar de Pesquisa em Representações, Educação e Sustentabilidade (GIPRES/UNEB). E-mail: teutato1@gmail.com 


\section{ABSTRACT}

CONTEXT OF INTERNATIONALIZATION IN CONTEMPORANEITY: CHALLENGES AND PERSPECTIVES OF THE UNIVERSITY OF THE STATE OF BAHIA

The purpose of this article is to discuss the development of internationalization actions in Higher Education in the last decades. It presents the dimensions of this concept as a way of apprehending the politics that intervene about educational decisions and how it can acquire different meanings depending on who is at the source of its "interpretation" and the context to which it applies. In the empirical field, he analyzes the role of the State University of Bahia (UNEB) in the context of contemporaneity, based on its internationalization actions. This is an exploratory and documentary research, whose results point to conceptual gaps, evidencing the need for greater investments in research that deepen the understanding of the various aspects concerning internationalization and note the challenges faced in UNEB for the implementation of an institutional policy of internationalization.

Keywords: Internationalization policy. Higher education. Contemporaneity.

\section{RESUMEN}

\section{CONTEXTO DE LA INTERNACIONALIZACIÓN EN LA CONTEMPORALIDAD: DESAFÍOS Y PERSPECTIVAS DE LA UNIVERSIDAD DEL ESTADO DE BAHIA}

El objetivo de este artículo es discutir sobre el desarrollo de las acciones de internacionalización en la Educación Superior, a lo largo de las últimas décadas. Se presentan las dimensiones de este concepto como forma de aprehender la política que interviene sobre las decisiones educativas y cómo puede adquirir significados diferentes dependiendo de quién está en la fuente de su "interpretación" y del contexto al que se aplica. En el campo empírico, analiza el papel de la Universidad del Estado de Bahía (UNEB) en el contexto de la contemporaneidad, a partir de sus acciones de internacionalización. Se trata y una investigación exploratoria y documental cuyos resultados apuntan a lagunas conceptuales, evidencian la necesidad de mayores inversiones en investigaciones que profundizan el entendimiento de los diversos aspectos concernientes a la internacionalización y constatan los desafíos enfrentados en la UNEB para la implementación de una política institucional de internacionalización

Palabras clave: Política de internacionalización. Educación superior. Contemporaneidad.

\section{Introdução}

O objetivo deste texto é discutir sobre a internacionalização em caráter institucional, levando-se em consideração as universidades brasileiras e estrangeiras, a fim de compreender o seu conceito e as suas ações. Nesse sen- tido, intentamos levar o leitor a uma reflexão sobre a necessidade de evidenciar os fatos sociais que envolvem as tendências da internacionalização enquanto fenômeno da globalização e suas implicações na educação superior. 
As motivações para a internacionalização nas universidades dependem do contexto e das influências políticas as quais estão inseridas. Os fatos recentes gerados pela contemporaneidade, como a globalização e a internacionalização das políticas educacionais (KNIGHT, 2004), interpelam tanto as instituições desse terreno quanto os educadores. Os seus impactos colocam em causa os desafios de (re)aprender e (re)conhecer formas de agir diante das inovações científico-tecnológicas e das reformas da educação em ascendência em uma sociedade marcada pela intensificação dos fenômenos diaspóricos e/ou migratórios, da mobilidade incessante e da diversidade ocasionada pela globalização mundial.

A internacionalização, enquanto política dos dias atuais na educação superior, começou a ter maior popularidade a partir do início dos anos 80 do século passado (KNIGHT, 2002). Todavia, é preciso ressaltar que as decisões tomadas após a II Guerra Mundial culminaram com a fundação da Organização das Nações Unidas (ONU), em 1948. Seu surgimento esteve vinculado à busca de uma reconfiguração do conceito de humanidade e unificação para os acordos de paz mundial no pós-Guerra. Este fato social foi, portanto, um dos marcos do fortalecimento dos discursos que constituem os debates da política externa norteadores das políticas de internacionalização que são multiplicados com intervenções das organizações internacionais, cujo objetivo é controlar as relações internacionais entre os países signatários para os acordos firmados no final da década de 1940.

A partir da década de 1990, com a expansão das práticas de internacionalização da educação superior, os fatos gerados por esse tipo de prática nas formações sociais passaram a ser tematizados em trabalhos de pesquisas, em documentos de políticas e na retórica administrativa dessas mesmas formações (HUDZIK, 2011). Com esse avanço, o conceito de internacionalização enquanto política que intervém nas decisões educacionais pode adquirir significados diferentes, dependendo de quem está na fonte de sua "interpretação" e do contexto ao qual ela se aplica com o objetivo de ser concretizada. Embora nem todos os países tenham o mesmo entendimento de suas finalidades e resultados, constata-se recentemente uma ascensão considerável de ações que têm impulsionado a sua abrangência enquanto estratégia positiva na formação acadêmica (MIURA, 2006).

A esse respeito, o relatório da Association of International Educators (NAFSA), conduzido por Hudzik (2011), traz dados recentes de pesquisas descrevendo as últimas décadas como um período marcado pela emergência de fatores sociais novos e poderosos que vêm revigorando as dimensões internacionais do ensino superior, o fluxo transfronteiriço dos estudantes e pesquisadores, as ideias e a expansão do currículo acadêmico. Esses dados, compilados durante o período de 2010 a 2015, sinalizaram um aumento de $83 \%$ de matrículas realizadas no ensino superior de instituições estrangeiras. Esses resultados prefiguram um crescimento ainda maior pela demanda de até $150 \%$ até 2025 (HUDZIK, 2011). Portanto, esta nova ordem educativa mundial carrega em si práticas seculares de internacionalização em massa, como é o caso da mobilidade nas trocas de conhecimento, o comércio, as forças sociais, as trocas de ideias que impulsionaram e tornaram ainda mais significante a internacionalização da educação nos dias atuais (HUDZIK, 2011).

Segundo Knight (2002), a literatura identifica quatro encaminhamentos sobre essa questão. No primeiro momento, as universidades matriculariam os seus estudantes e, em seguida, os enviariam acompanhados do corpo docente ao exterior, ambos carregando expectativas e interesses pela concorrência econômica e/ou por questões de diversidade cultural difundidas por suas instituições. Em segundo lugar, elas desenvolveriam programas, conferências e cursos no exterior para motivar a mobilidade acadêmica e o compartilhamento de informações. Em terceiro, firmariam acordos de parcerias e definiriam rumos para pesquisa e finalidades de recursos financeiros. 
Este fato leva a questionamentos de que a internacionalização estaria mais direcionada ao mercado e à economia do que para a formação educacional. Finalmente, as universidades internacionalizariam os seus currículos por meio da inclusão de elementos culturais e globais. Tudo isso requer (re)ajustes estruturais, em todas as instâncias institucionais.

Assim, tendo por base as instruções de Knight (2004), no caso brasileiro, as motivações que impulsionam as atividades nesse contexto não são totalmente diferentes de outros países, exceto aqueles que têm um sistema privado de educação e que concedem autonomia às suas universidades para que elas se coloquem como balcão de negociação e venda de programas de intercâmbio, como ocorre no Canadá, nos Estados Unidos, na Inglaterra e em outros países.

Esse contexto nos convida, a partir das diversas realidades da abordagem interdisciplinar, desvelar simultaneidades, tensões, confrontos, contradições e mudanças que nos permitem aproximações e distanciamentos sobre o fenômeno da internacionalização na educação superior.

Para tal, à luz da literatura, iniciamos com uma breve discussão sobre conceitos e significados de internacionalização, assim como estratégias que abordam os tipos de procedimentos, atividades e iniciativas nesse domínio. Em seguida, apresentamos as ações de internacionalização desenvolvidas pela Universidade do Estado da Bahia (UNEB). E, finalmente, colocamos em destaque as perspectivas e os desafios enfrentados pela universidade para avançar na sua política institucional de internacionalização.

\section{Abordagem metodológica e considerações conceituais sobre internacionalização}

Em consonância com os objetivos para realização deste trabalho, esta pesquisa se caracteriza como de abordagem qualitativa documental e de natureza exploratória, pois existem poucos estudos acerca do fenômeno da internacionalização da educação superior.

Fizemos uso da análise do conteúdo dos discursos em livros e artigos, bem como dos documentos institucionais e registros em arquivos físicos e eletrônicos. Desse modo, documentos disponíveis dos últimos cinco anos em arquivos de domínio público foram coletados, a saber: informações constantes nos sítios institucionais, nos planos de desenvolvimento institucionais vigentes, em relatórios de gestão e em planos de metas.

Na primeira etapa, buscamos na literatura existente dois eixos de pesquisa: 1) elaboração do quadro conceitual de internacionalização e de sua relação com alguns conceitos relevantes, dentre eles a globalização, a educação intercultural e multicultural, a educação internacional, entre outros (ALTBACH; KNIGHT, 2004); e 2) estratégias que abordam os tipos de procedimentos, atividades e iniciativas nesse domínio.

Sobre o quadro conceitual e seu significado, embora os avanços nessa área tenham sido positivos no que diz respeito à elaboração de seu quadro conceitual, expõe que as pesquisas sobre internacionalização ainda têm focado suas abordagens apenas na conceitualização do campo de estudo (DE WIT, 2005). Segundo esse autor, as abordagens estão pautadas pela recorrência do entendimento puramente teórico, o que deixa um vazio nas interpretações simplistas feitas pelos pesquisadores desta linha de investigação. 0 foco dado por essas pesquisas está mais direcionado às razões e motivações para a internacionalização, incluídas aí as orientações do mercado predominante, pouca atenção aos currículos, quase nenhuma sobre as questões pedagógicas, a ausência de ações e as perspectivas dos estudantes.

A pesquisa de Lima e Maranhão (2009) identifica que os estudos sobre internacionalização têm avançado sobre as dimensões da educação superior, explorando suas implicações sobre as políticas de governo, o planeja- 
mento estratégico, a gestão institucional e a qualidade da duração que, por sua vez, envolve a internacionalização dos currículos e do papel das línguas e da cultura como via possível para avançar nesta direção. Lima e Maranhão (2009) defendem que, ao longo dos anos de globalização, não houve apenas mudanças no panorama educacional, mas surgiram novos termos e terminologias.

Dessa forma, as questões e os impactos da globalização deveriam ser vistos pelas instituições como um contexto no qual o planejamento dos programas e currículos viessem a funcionar de forma proativa. A expectativa de uma educação que possa responder a esses efeitos contextuais e os serviços prestados pelo sistema educacional deveriam estar voltados para a preparação de graduandos de forma que eles venham a compreender criticamente as questões globais e seus efeitos locais sobre as pessoas e comunidades. Como muito bem sinaliza Santos (2015), viver e trabalhar em um mundo onde as fronteiras nacionais são permeáveis, as informações e as ideias fluem em uma velocidade relâmpago, onde as comunidades, culturas, línguas, atitudes e valores teriam, através da internacionalização, uma expectativa para atingir objetivos e resultados positivos. A esse respeito é preciso levar em conta que as transformações no âmbito acadêmico só seriam possíveis com o empreendimento de ações que promovessem a disseminação do conhecimento, considerando que sua produção depende da interação humana.

Conceitualmente, a internacionalização corresponde ao "processo de integrar uma dimensão internacional, intercultural ou global com o objetivo, as funções ou o oferecimento do ensino pós-secundário" (KNIGHT, 2004, p. 2). Nessa perspectiva, pode manifestar-se de diferentes formas, como promovendo a mobilidade física dos indivíduos, a cooperação acadêmica de pesquisadores, professores e estudantes, bem como a parceria transnacional entre universidades de diferentes partes do mundo, envolvendo múltiplos atores.
Na educação superior, a internacionalização equivale, portanto, a um movimento de grande abertura dos países às relações sociais externas visando à ampliação de competência diversas, como, por exemplo, educacionais, científicas e tecnológicas. Concretamente, ela pode se manifestar pelo crescente aumento da movimentação transnacional de pesquisadores, estudantes e professores universitários. 0 conhecimento mútuo gerado por esse movimento acontece em contextos igualmente diversificados: social, educacional, cultural, político, geográfico, econômico e linguístico, dentre outros.

Laus (2012) inicia seu trabalho conceitual com uma provocação interessante: internacionalizar para que e para quem? Nesse sentido, analisar o contexto (políticas públicas, história e geografia locais e mundiais) e os atores: Organização das Nações Unidas para a Educação, a Ciência e a Cultura (UNESCO); Organização para a Cooperação e o Desenvolvimento Econômico (OCDE); e Banco Mundial, por exemplo, envolvidos em um processo de internacionalização, faz-se necessário. Assim, essa autora realiza sua pesquisa com base no seguinte conceito:

[...] a internacionalização de uma Universidade corresponde ao processo de diálogo (trabalhos conjuntos, cooperação, intercâmbio, conflitos e problemas surgidos) com outras Universidades ou organizações variadas (empresas, governos, agências internacionais, ONGs) do mundo exterior à fronteira nacional na concepção, desenvolvimento ou implementação de suas funções de ensino, pesquisa e extensão. (LAUS, 2012, p. 81).

Lima e Maranhão (2009) trazem a ideia de internacionalização ativa e passiva. A primeira seria a forma como os países centrais praticam a internacionalização, e traz consigo a ideia de dominação de supremacia. Nesse conceito, cabe aos países como Estados Unidos e os da Europa ocidental atrair estudantes a fim de que possam ser qualificados a ingressarem no mercado de trabalho mundial, desenvolvendo habilidades que servem a esse propósito. As 
autoras alertam que esse processo é duplamente benéfico aos países do Norte, já que receber estudantes implica o recolhimento de taxas e impostos, além da manutenção de um modo de produção que lhes é conveniente. Num primeiro momento, para os alunos que buscam esses países também há vantagens, pois há em seus locais de origem uma valorização dos saberes externos. As autoras alertam para uma possível dominação cultural dos protagonistas dessa internacionalização ativa, pois eles concentram a imensa maioria dos estudantes internacionais. Assim, costumes e vivências locais passariam a ser reproduzidos em nível mundial.

Já aos países emergentes restaria a internacionalização passiva, ou seja, receber conhecimento dos países centrais. Aqui percebe-se que há um criterioso processo de seleção entre o restrito número de intelectuais que merecem ter a experiência internacional, que não se restringe apenas à mobilidade. 0 processo passivo serviria para consolidar as diferenças socioeconômicas e culturais tanto nacionalmente quanto em nível global, entre as nações.

É desse modo que passamos a reconhecer a grande variedade conceitual existente no campo da internacionalização da educação superior e, mais ainda, como a falta de consenso nessa área pode dificultar a prática e os rumos da internacionalização, inclusive em termos de políticas públicas que compreendem o fator estratégico da mesma para o avanço da educação superior. A esse respeito, Laus (2012, p. 79) analisa que existe um sentimento de falsa convergência na literatura, não havendo, desta forma, um consenso sobre "os sentidos, as razões e os rumos da internacionalização da educação superior".

De acordo com Knight (2004), na discussão da internacionalização da educação é preciso se manter atento tanto aos benefícios quanto aos riscos e às consequências não intencionais desse processo. Nessa perspectiva, a autora enfatiza:

[...] embora há múltiplos e variados benefícios na internacionalização, manter o foco somente nos benefícios significa ignorar os riscos e as consequências negativas não intencionais envolvidas. A fuga de cérebros decorrente da mobilidade acadêmica internacional é um exemplo de efeito adverso. 0 atual conceito de circulação de cérebros não reconhece a ameaça da mobilidade acadêmica nem a grande disputa por cérebros provenientes dos países situados no extremo inferior da cadeia intelectual. Além disso, a busca pela qualificação internacional está levando à recorrente emissão de títulos fraudulentos oferecidos por fábricas de diploma. (KNIGHT, 2004, p. 25).

Nas últimas décadas, os programas de mobilidade vêm se fortalecendo e se destacando como uma das estratégias mais férteis para a cooperação acadêmica internacional. Todavia, ainda que dotados de grande relevância, esses programas constituem a parte mais visível da internacionalização, pois, na verdade, existem várias outras possibilidades. Isto porque as políticas estatais e institucionais "promovem a internacionalização diversificando e fortalecendo a base tecnológica e científica de desenvolvimento sustentável enquanto se preservam interesses nacionais e incentivos para implementar redes até a excelência na investigação tecnológica e científica" (LAUS; MOROSINI, 2005, p. 148).

A evidência está nos resultados e no novo comportamento da Academia e da sociedade científica, que reconhecem, privilegiam e valorizam ainda mais toda manifestação intelectual, especialmente a que contém algum componente internacional (STALLIVIERI, 2017). A manifestação da internacionalização passa a ser percebida em todos os ambientes das instituições de Ensino Superior, ou seja, ela é necessariamente uma manifestação transversal que contempla as atividades de gestão além do conhecido tripé da educação superior - ensino, pesquisa e extensão.

Alianças estratégicas podem ser vistas como lógicas, tanto acadêmicas quanto econômicas, tanto como uma lógica motriz, quanto como um meio ou instrumento de internacionalização. A mobilidade internacional de estudantes e acadêmicos e iniciativas colaborativas de pesquisa 
e educação estão sendo vistas como maneiras produtivas de desenvolver laços geopolíticos mais estreitos e relações econômicas. Houve uma mudança de alianças de propósitos culturais para aquelas de fins econômicos. Isto é especialmente verdadeiro em nível regional, onde os países estão tentando alcançar uma integração econômica e política mais forte com seus vizinhos, aumentando suas atividades de educação internacional com base regional. 0 desenvolvimento de alianças estratégicas por meio da internacionalização do ensino superior é visto como uma maneira de desenvolver uma cooperação regional bilateral mais estreita e ganhar vantagem competitiva.
Embora possamos observar na literatura diversos modelos que propõem a internacionalização da educação superior, um dos modelos importantes é o proposto por Knight (2004), que compreende sete fases: análise de contexto, conscientização, razões, abordagem, comprometimento, planejamento e operacionalização. As fases podem ocorrer em diferentes direções e ordens, mas estão interconectadas, pois se retroalimentam uma em decorrência da outra. Knight (2004) propõe, ainda, que essas fases façam parte de uma estratégia institucional para a internacionalização e que ocorram de forma integral, envolvendo todos os níveis de gestão da instituição (Figura 1).

Figura1 - Ciclo da internacionalização

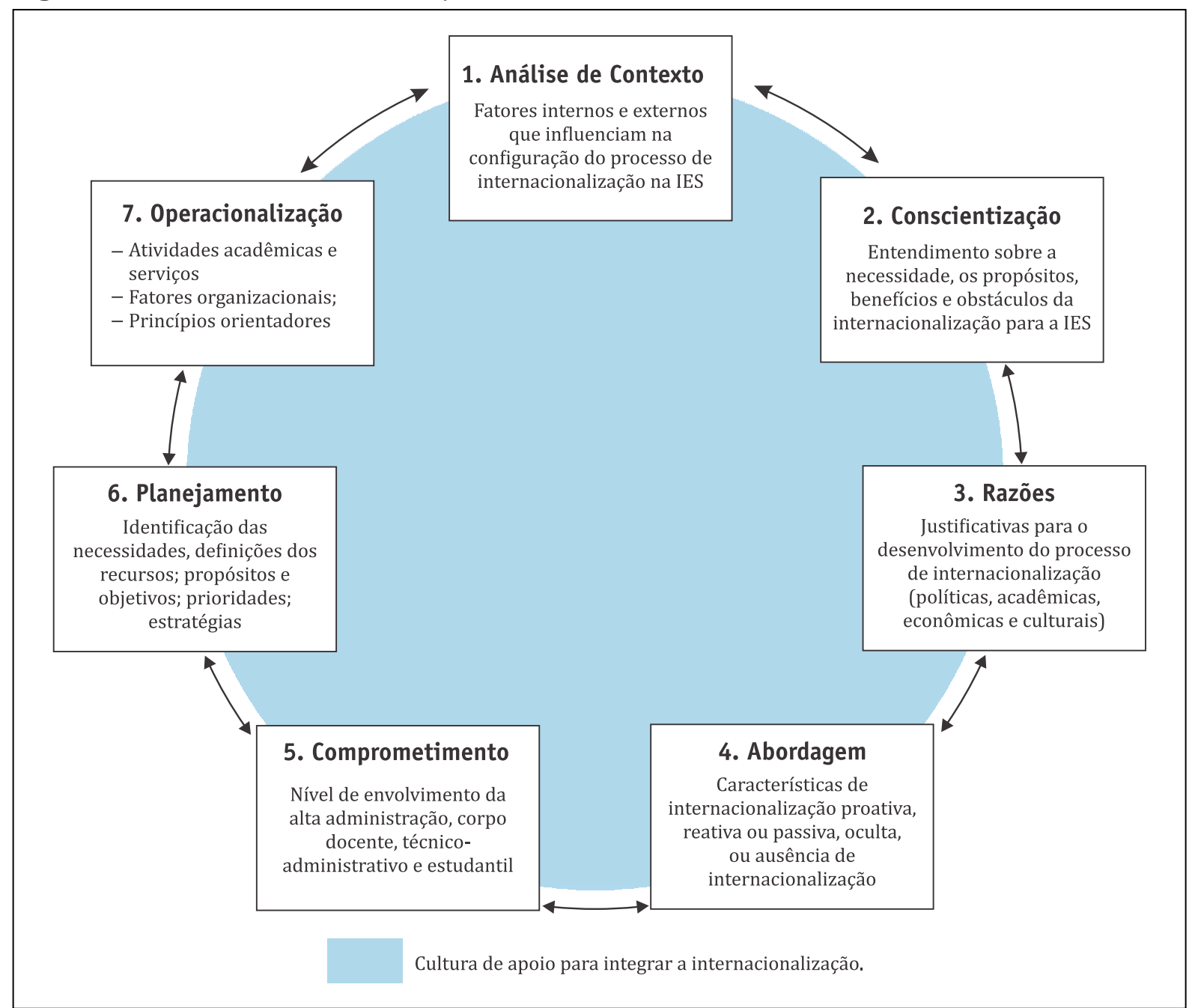

Fonte: Knight (2004, p. 12).

Ao optar pela implantação de um modelo de internacionalização, é fundamental que a instituição tenha clareza de seu contexto inter- no e externo a fim de se conscientizar de sua missão como organismo promotor da educação superior, envolvendo as razões, a abordagem 
e o comprometimento. Desse modo, adequar suas ações estruturantes com os objetivos que pretende atingir com seu planejamento. Ou seja, definir ações de internacionalização alinhadas com o plano de política institucional de internacionalização, com metas estabelecidas e com os responsáveis pela sua execução, avaliação e pelo posterior redirecionamento de cada uma delas.

Torna-se mister que as autoridades das Instituições de Ensino Superior (IES) estabeleçam critérios claros no momento da realização do diagnóstico que identifica o nível de internacionalização de suas ações, de seus programas ou de seus projetos. Tais critérios podem basear-se em consultorias internacionais já existentes, ou podem ser criados pela própria instituição, observando aspectos de natureza interna e externa.

Para a realização de um bom plano de inserção internacional, primeiramente a instituição deve buscar reconhecer suas potencialidades, 0 que tem de bom a oferecer, e quais as necessidades que possui para receber a cooperação de outras instituições congêneres. A melhor forma para chegar a esse entendimento é mediante a realização de um detalhado diagnóstico institucional.

A constante interlocução com as demais Pró-Reitorias de graduação, Pós-graduação, investigação, extensão e de administração é fundamental, pois, dessa forma, a área de relações internacionais estará atenta a todos os movimentos e às demandas institucionais em direção à correta internacionalização.

\section{UNEB: desafios e perspectivas da internacionalização em contexto de multicampia}

A Universidade do Estado da Bahia (UNEB) é uma Autarquia em Regime Especial, vinculada à Secretaria Estadual de Educação, estruturada sob forma de um Sistema Multicampi de Educação Superior e foi criada pela Lei Delegada no
66 , de $1^{\circ}$ de junho de 1983 . Teve seu funcionamento autorizado pelo Governo Federal através do Decreto Presidencial no 92.937, de 17 de julho de 1986. Em 1997, com a vigência da Lei Estadual $n$ o 7.176, a estrutura organizacional passou a ser instituída por departamentos, caracterizando-a como multicampi (BOAVENTURA, 2009).

Atualmente, a UNEB agrega 29 departamentos, com fixação geográfica em todas as regiões do Estado e com sede em 24 municípios baianos. Além disso, a universidade atua em aproximadamente 417 municípios do estado por meio de programas e ações extensionistas, em convênio com organizações públicas e privadas. 0 contexto da UNEB permite referenciar que a instituição é uma das maiores universidades públicas do Brasil, com destaque à diversidade na oferta de cursos de graduação e pós-graduação, nas modalidades presencial e a distância, em diferentes áreas do conhecimento.

Em seu portifólio, a instituição dispõe, atualmente, de mais de 170 opções de cursos presenciais e a distância, distribuídos nos níveis de graduação e pós-graduação, este último disponível nas modalidades lato sensu e stricto sensu (UNIVERSIDADE DO ESTADO DA BAHIA, 2018a). Vale ressaltar que a pós-graduação na Uneb objetiva a qualificação de profissionais pesquisadores responsáveis por uma produção científica, tecnológica e cultural de qualidade na Universidade. Em 2001, houve a implantação do primeiro curso de mestrado, através do Programa de Pós-Graduação em Educação e Contemporaneidade (PPGEduC), e, em 2009, o programa implantou o curso em nível de doutorado. Várias ações realizadas para a PósGraduação trouxeram ampliação de programas e cursos de pós-graduação lato sensu e stricto sensu, nas diversas áreas de conhecimento, ofertados em Salvador e no interior da Bahia.

Cabe destacar a característica multicampi da UNEB à medida que a gestão de sua internacionalização requer abrangência de todas as suas unidades, circunscritas geograficamente 
nas três regiões do estado, a saber: Mata Atlântica, Semiárido e Cerrado. A Figura 2 ilustra a distribuição dos multicampi da UNEB e suas ações de internacionalização pelos 27 (vinte e sete) Territórios de Identidade da Bahia, que se anunciam como necessários à gestão social de desenvolvimento do Estado, diante das singularidades apresentadas pela população, com o crescimento e legitimidade do processo de expansão geográfica.

Figura 2 - Multicampi da UNEB nos Territórios de Identidade da Bahia e suas Ações de Internacionalização

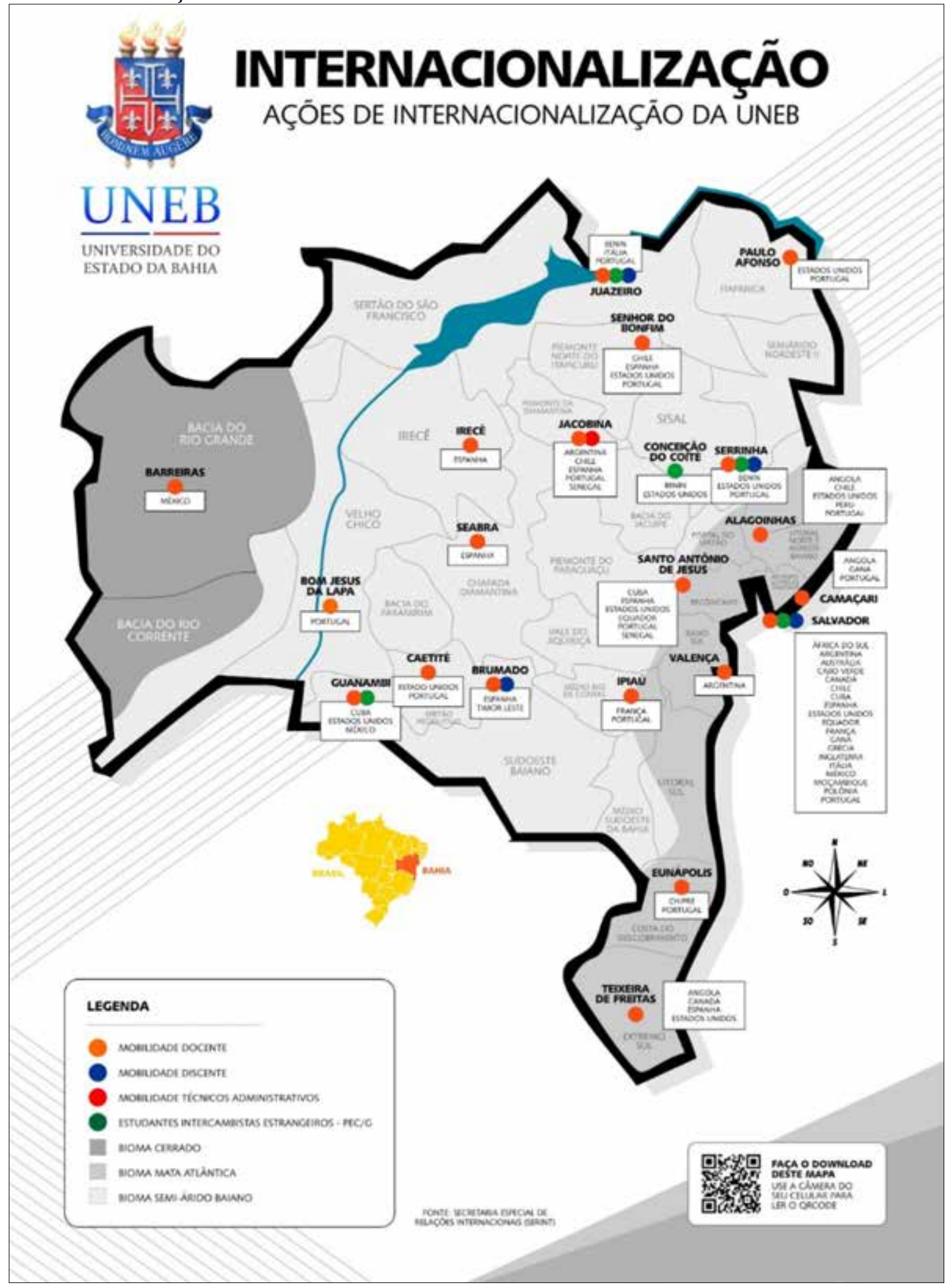

Fonte: Universidade do Estado da Bahia (2019). 
Nesse sentido, a interiorização da UNEB pode atuar em favor de seu processo de internacionalização à medida que requer a gestão de um modelo educacional interligado que necessita funcionar em harmonia no conjunto de suas ações e relações. No contexto global atual, em que a cooperação internacional e a integração intercultural são características inerentes à contemporaneidade, o modelo multicampi ressalta as potencialidades do processo de internacionalização. Fialho (2012) pondera que a complexidade do modelo de universidade multicampi muito se assemelha à dinâmica de internacionalização universitária por envolver questões relativas ao rompimento das barreiras do tempo e do espaço em vista dos processos de produção e socialização do conhecimento científico e tecnológico.

Quanto às atividades de internacionalização, não há evidência de uma distribuição equitativa da participação de discentes, docentes e técnicos nos programas de acordos e convênios de parceria internacional. Percebe-se ações localizadas, para atender demandas específicas de determinados Territórios. Com isso, Thiengo, Bianchetti e De Mari (2018) alertam que a capacidade de governança de instrumentos de ação intrainstitucional, bem como o fortalecimento de concepções de universidade e ciência cada vez mais pragmáticas e utilitárias, devem ter desdobramentos no âmbito das formulações políticas e no planejamento das ações universitárias.

\section{Desafios e perspectivas de institucionalização da Secretaria Especial de Relações Internacionais (SERINT)}

Do ponto de vista da gestão universitária, a partir do novo projeto de gestão "UNEB Democrática e de Qualidade 2014-2017" (UNIVERSIDADE DO ESTADO DA BAHIA, 2017) surgiu a Secretaria Especial de Rela- ções Internacionais (SERINT) em substituição à Assessoria para Cooperação Internacional (ASSECI). Essa Secretaria passa a ser responsável pela formulação e execução da política de internacionalização da UNEB, com a missão de promover e expandir a sua atuação internacional, em consonância com as diretrizes estabelecidas no seu Plano de Desenvolvimento Institucional - PDI 2013/2017, que reconhece a complexidade das relações universitárias no ambiente global, apontando para a internacionalização, especialmente por meio da mobilidade acadêmica internacional e do desenvolvimento de projetos interinstitucionais, como um fator de relevância para o desenvolvimento institucional (UNEB, 2013). Nesse contexto, os fenômenos externos são destacados como oportunidades de melhorias na oferta de seus serviços e no aumento da visibilidade institucional no cenário internacional. Percebemos, assim, que a UNEB compreende o potencial estratégico da internacionalização face às grandes transformações que estão ocorrendo na sociedade globalizada.

Para tal, no regimento foram pensadas 6 (seis) ações estruturantes como forma de contribuir com o processo de criação e implantação de uma política institucional de internacionalização: Fortalecimento e ampliação de parcerias com centros de referência internacionais; Promoção e inserção da UNEB no cenário nacional e internacional, por meio da cooperação interinstitucional para o desenvolvimento acadêmico, cultural, social, científico e tecnológico, intercâmbio de práticas, mobilidade internacional de docentes e demais servidores, e discentes; Incentivo à mobilidade internacional de docentes, discentes e demais servidores técnico-administrativos; Promoção e divulgação da produção científica, tecnológica, cultural e acadêmica da universidade no exterior; Auxílio à comunidade universitária em suas relações acadêmicocientíficas com entidades externas, públicas ou privadas, nacionais ou internacionais; 
Coordenação e operacionalização de celebração de acordos, convênios e parcerias de âmbito nacional e internacional, relacionados às atividades acadêmico-científicas.

A estruturação do setor de relações internacionais da UNEB enquanto uma Secretaria Especial com status de órgão executivo é indício da compreensão da internacionalização como estratégia para o desenvolvimento institucional. Os princípios orientadores dessa secretaria revelam a preocupação de que a dimensão internacional possa permear todos os espaços da instituição, de forma que tal compromisso vem sendo construído à medida que seus atores se acercam da importância da internacionalização.

Pelos dados levantados junto a instituição, verificamos que a UNEB demonstra preocupação com a sua inserção internacional desde o ano de 2007, quando solicitou adesão ao Programa de Estudantes-Convênio de Graduação (PEC-G), desenvolvido com base na assinatura de protocolos conjuntos com prazos indeterminados entre dois ministérios: o Ministério da Educação (MEC) e o Ministério das Relações Exteriores (MRE), ainda com a participação das Instituições de Ensino Superior e com as Missões Diplomáticas e Repartições Consulares. Esse programa destina-se aos estudantes oriundos de 56 países localizados na América Latina, Caribe, África e Ásia com os quais o Brasil mantém acordos de cooperação nas áreas cultural, científica e tecnológica. Ao todo são 24 países da África, 25 das Américas e 7 da Ásia. De acordo com o MRE, a África é o continente de origem da maior parte dos estudantes PEC-G, com destaque para os Países Africanos de Língua Oficial Portuguesa (PALOP).

0 recebimento dos primeiros alunos-convênio PEC-G na UNEB ocorreu no ano de 2009. O fluxo desses alunos está relacionado diretamente ao processo de internacionalização da educação superior, considerando a dinâmica da contemporaneidade e a circulação cultural e social das pessoas, que possibilita atividades de cooperação educacional internacional. Apontando, no que diz respeito ao entendimento da internacionalização da educação superior, analisando os benefícios, os obstáculos e as resistências para condução desse processo. Ou seja, despertando sua conscientização para o potencial de elevação de sua visibilidade internacional e a possibilidade de melhoria de seus processos internos nas dimensões do ensino, pesquisa e extensão, como principais benefícios do processo de internacionalização.

Atualmente, para a SERINT, as prioridades para internacionalização estão na institucionalização e normatização de seus processos, além da necessidade de maior divulgação e transparência das ações de modo a democratizar o conhecimento acerca das oportunidades existentes para a comunidade e socializar, enfatizando especialmente as atividades de estudo no exterior. Por sua vez, aponta o fortalecimento da pós-graduação como o principal foco de desenvolvimento da internacionalização.

Acerca do modo como tem-se dado a implementação e o desenvolvimento da internacionalização, destaca-se também a concepção de processos para os acordos de cooperação científica e tecnológica bilateral que têm sido feitos através de acordos/convênios inter-universidades. Os acordos/convênios existentes são, normalmente, gerenciados por docentes das unidades interessadas, cabendo à SERINT o apoio na fase preliminar, assessorando na elaboração dos documentos e, posteriormente, no acompanhamento das atividades de ensino e pesquisa.

No período de 2015 a 2018 foram estabelecidos 35 Acordos de Cooperação Internacional, vigentes (Argentina, Chile, Estados Unidos, França, Itália, Moçambique, Peru, Portugal, Reino Unido) com 57 docentes dos diversos territórios de identidade em mobilidade nos diversos países (Quadro 1). 
Quadro 1 - Docentes em mobilidade no exterior

\begin{tabular}{|c|c|c|c|}
\hline $\begin{array}{l}\text { DEPARTAMENTO/ } \\
\text { CAMPUS }\end{array}$ & PAÍS DESTINO & MOTIVO & QTD. \\
\hline DCH - I & $\begin{array}{l}\text { Espanha/ França/ } \\
\text { Moçambique }\end{array}$ & Doutorado/Pós-Doutorado & 2 \\
\hline DEDC - I & Portugal/Itália/Espanha & $\begin{array}{l}\text { Participação em Evento/Participação em Banca } \\
\text { e Palestra/Pós-Doutorado }\end{array}$ & 5 \\
\hline DCV - I & Cuba/Portugal & Missão Científica/Participação em Evento & 4 \\
\hline DCET - I & Canadá & Participação em Evento & 3 \\
\hline DCET - II & Portugal/EUA & Participação em Evento/Pós-Doutorado & 3 \\
\hline DEDC - II & Peru & Missão Científica & 1 \\
\hline DCH - III & Itália & Participação em Banca de Doutorado & 1 \\
\hline DCH - IV & $\begin{array}{l}\text { Chile/Chile/Portugal/ } \\
\text { Espanha/ Senegal /Argentina }\end{array}$ & Doutorado/Participação em evento & 7 \\
\hline $\mathrm{DCH}-\mathrm{V}$ & $\begin{array}{l}\text { Portugal/ Estados Unidos } \\
\text { da América/Espanha/Cuba/ } \\
\text { Senegal }\end{array}$ & $\begin{array}{l}\text { Doutorado/Participação em Evento/ } \\
\text { Apresentação de Trabalho }\end{array}$ & 5 \\
\hline DEDC - VII & Chile/Portugal & Participação em Evento/Doutorado & 2 \\
\hline DEDC - VIII & EUA/Portugal & Missão Científica/Participação em Evento & 2 \\
\hline DEDC - X & $\begin{array}{l}\text { Canadá/Espanha/Angola/ } \\
\text { EUA }\end{array}$ & Doutorado/Participação em Evento & 4 \\
\hline DEDC - XII & Cuba & Participação em Evento & 1 \\
\hline DEDC - XIV & Portugal & Doutorado & 1 \\
\hline DEDC - XV & Argentina & Doutorado & 1 \\
\hline DCHT - XVI & Espanha & Participação em Evento & 1 \\
\hline DCHT - XVIII & Portugal & Doutorado & 1 \\
\hline DCHT - XIX & EUA/Espanha/Portugal/Itália & Participação em Evento/Pós-Doutorado & 7 \\
\hline DCHT - XX & Espanha & Participação em Evento & 1 \\
\hline DCHT - XXI & Portugal / França & Participação em Evento & 2 \\
\hline DCHT - XXIII & Espanha & Participação em Evento & 1 \\
\hline SERINT & Cuba & Missão a serviço & 1 \\
\hline CAECDT & Cuba & Participação em Evento & 1 \\
\hline TOTAL & & & 57 \\
\hline
\end{tabular}

Fonte: Universidade do Estado da Bahia (2018b, p. 18). 
Ainda constatamos 15 intercâmbios estudantis, sendo 8 (oito) para Cuba e 7 (sete) para Portugal, e 2 intercâmbios para servidores técnico-administrativos, 1 para a Argentina e 1 para Cuba. Fazemos parte da Associação Brasileira de Educação Internacional (FAUBAI), do Grupo Coimbra de Universidades Brasileiras (GCUB), do Projeto CAMINOS, para mobilidade acadêmica, cuja coordenação está a cargo do Observatório das Relações União Europeia -América Latina (OBREAL), da Universidade de Barcelona, Espanha, e do Programa de Formação de Professores de Educação Superior de Países Africanos (ProAfri), edição Moçambique.

Para implementação de uma política institucional de internacionalização na UNEB, a SERINT trabalha na elaboração do Manual de Procedimentos de Internacionalização, na revisão do Regimento e do Plano Institucional de Internacionalização, nas minutas de resoluções de acordos e convênios, na mobilidade docente, discente e de servidores técnico-administrativos e no acompanhamento de editais internos e externos.

\section{Considerações finais}

No contexto atual, por meio das portarias e comissões instituídas pelo princípio da governança, busca-se desenvolver o processo de internacionalização de forma institucionalizada. Nesse sentido, as evidências apontadas neste artigo revelam um modelo de internacionalização que prioriza as ações desenvolvidas nos Campi em seus territórios de identidade.

Esse modelo se justifica pelo comprometimento do corpo docente, que protagoniza as relações que impulsionam as ações de internacionalização, na medida em que se mobiliza com os seus grupos de pesquisa, abrindo o leque de periódicos para publicações, difundindo as produções científicas da instituição e mobilizando os estudantes a se engajarem em atividades de intercâmbio internacional. Nesse sentido, a internacionalização na UNEB se projeta com: a) o alcance de uma visibilidade e reconhecimento internacionais; b) a produção de conhecimento; e c) o desenvolvimento da comunidade acadêmica como um todo, especialmente através da mobilidade acadêmica internacional.

Em relação à dimensão da operacionalização, esforços de ações conjuntas e articulação interinstitucional são evidenciados, tal qual a preocupação em apoiar, por meio de editais de bolsas de estudo, o desenvolvimento de ações de mobilidade internacional. A gestão de seus acordos de cooperação internacional se sobressai por suas fragilidades de operacionalização e baixa efetividade.

Em relação ao planejamento para a internacionalização, os indícios levantados na UNEB apontam para uma carência de estratégias institucionais para esse processo. Assim, apesar de poucas estratégias programáticas de internacionalização - tais como intercâmbio de estudantes, acordos de pesquisa -, é possível perceber a preocupação da UNEB em desenvolver estratégias organizacionais, que envolvem desde o desenvolvimento do currículo até o compromisso expresso da administração com a internacionalização e o reconhecimento da dimensão internacional na missão da universidade e no planejamento (presente, até o momento, ao menos no âmbito da pós-graduação).

Não obstante, é sabido, aos obstáculos à internacionalização da educação superior na UNEB fazemos uma análise dos aspectos estruturais - desde inadequação no sítio institucional à baixa proficiência em línguas estrangeiras por parte da comunidade acadêmica como um todo. Dessa forma, retomamos o argumento de Knight (2004) ao enfatizar que a internacionalização não pode ser vista como questão exclusiva da alta administração. Isso é parte do processo de conscientização da necessidade e dos propósitos da internacionalização e fruto da clareza acerca das razões para internacionalizar, além de um esforço integrado para torná-la parte do fazer educacional. Deste modo, a UNEB se insere nacionalmente 
e internacionalmente envolvida com as novas perspectivas e mudanças sociais por meio de pesquisas realizadas, dos prêmios recebidos, pela participação nos programas de mobilidade e intercâmbio e, principalmente, pela sua relação com os seus stakeholders.

Ao mesmo tempo, aponta um trabalho de conscientização da comunidade acadêmica quanto à necessidade de expandir os processos que configuram internacionalização, por meio de palestras e workshops envolvendo a internacionalização. Há ainda menção de tratativas para a construção da versão em inglês e espanhol do sítio eletrônico da UNEB, o que demonstra que, apesar dos impasses, a instituição tem trilhado caminhos que visam à criação de uma cultura de internacionalização. Acreditamos que se baseando na indissociabilidade entre Ensino, Pesquisa e Extensão, em conjunto com boas práticas de gestão, os desafios constatados na implementação dos processos de internacionalização serão superados.

Por fim, considerando as lacunas conceituais existentes no campo dos estudos envolvendo a internacionalização da educação superior e, do mesmo modo, a complexidade com que se reveste esta temática na atualidade ao abranger fenômenos amplos e em constante mutação, ponderamos que este quadro tem impactado no processo de desenvolvimento da dimensão internacional na UNEB, refletindo a falta de institucionalização que obscurece os rumos da internacionalização nessa instituição. Assim, percebemos a necessidade de maiores investimentos em pesquisas que aprofundam o entendimento dos diversos aspectos concernentes à internacionalização no contexto das IES brasileiras, de modo a demarcar as singularidades e potencialidades deste processo e promover o fortalecimento e a consolidação de sua inserção internacional.

\section{REFERÊNCIAS}

ALTBACH, Phillip.; KNIGHT, Jane. Globalization and the university: myths and realities in unequal world. Tertiary Education and Management, v. 10, n 1, p. 3-25, mar. 2004.

ALTBACH, Phillip.; KNIGHT, Jane. An internationalization model: responding to new realities and challenges. In: DE WIT. et al (ed.). Internationalization of higher education in Latin America: the international dimension. Washington: World Bank, 2005. p. 1-40.

BOAVENTURA, Edivaldo Machado. A construção da universidade baiana: objetivos, missões e afrodescendência. Salvador: EDUFBA, 2009.

FIALHO, Nadia. Universidades estaduais no Brasil: pauta para construção de um sistema nacional articulado de educação. Revista da FAEEBA - Educação e Contemporaneidade, Salvador, v. 21, n. 38, p. 81-93, jul./dez. 2012.

HUDZIK, John. Internacionalización integral: del concepto a la acción. 2011. Disponível em: www. nafsa.org/_/File/_/comprehensive_izn_spanish. pdf. Acesso em: 29 abr. 2019.

KNIGHT, Jane. Internationalization remodeled: definition, approaches and rationales. Journal of Studies in International Education, v. 8, n. 1, p. 05-31, Spring 2004.

KNIGHT, Jane. Trade in higher education services: the implications of GATS. London: Observatory on Borderless Higher education, 2002. Disponível em: http://www.obhe.ac.uk. Acesso em: 02 mar. 2019.

LAUS, Sônia: A internacionalização da educação superior: um estudo de caso da Universidade Federal de Santa Catarina. 2012. 332 f. Tese (Doutorado em Administração) - Programa de Pós-Graduação em Administração, Universidade Federal da Bahia (UFBA), Salvador, 2012. Disponível em: http://www.adm.ufba.br/sites/default/files/ publicacao/arquivo/sonia_pereira_tese_final.pdf. Acesso em: 09 maio 2019.

LAUS, Sônia; MOROSINI, Marília. Internationalization of Higher Education in Brazil. In: DE WIT, H. et al (ed.). Higher education in Latin America: the international dimension. Washington: The World Bank, 2005. p. 111-147.

LIMA, Manolita; MARANHÃo, Carolina. O sistema de educação superior mundial: entre a internacionalização ativa e passiva. Avaliação, Campinas/Sorocaba, SP, v. 14, n. 3, p. 583-610, nov. 2009.

MIURA, Irene. 0 processo de internacionalização 
da Universidade de São Paulo: um estudo de três áreas de conhecimento. 2006. 381 f. Tese (Livre Docência) - Faculdade de Economia, Administração e Contabilidade de Ribeirão Preto (FEA/RP), Universidade de São Paulo (USP), Ribeirão Preto, SP, 2006.

SANTOS, Milton. Por uma outra globalização: do pensamento único à consciência universal. Rio de Janeiro: Record, 2015.

STALLIVIERI, Luciane. Internacionalização e intercâmbio: dimensões e perspectivas. Curitiba: Appris, 2017.

THIENGO, Lara Carlette; BIANCHETTI, Lucídio; DE MARI, Cezar Luiz. Rankings acadêmicos e universidades de classe mundial: relações, desdobramentos e tendências. Educação e Sociedade, Campinas, v. 39, n. 145, p. 1041-1058, out./ dez. 2018.

UNIVERSIDADE DO ESTADO DA BAHIA (UNEB). Plano de Desenvolvimento Institucional 20132017. Salvador, 2013. Disponível em: http://www. uneb.br/files/2015/03/pdi_uneb.pdf. Acesso em: 23 mar. 2019.

UNIVERSIDADE DO ESTADO DA BAHIA (UNEB). Relatório Anual de Atividades de 2016. Salvador,
2017. Disponível em: http://www.uneb.br/ proplan/files/2010/06/RAQ20161.pdf. Acesso em: 24 mar. 2019.

UNIVERSIDADE DO ESTADO DA BAHIA (UNEB). Plano de Desenvolvimento Institucional 20182021. Salvador, 2018a. Disponível em: http://www. uneb.br/files/2018/03/pdi_uneb.pdf. Acesso em: 24 mar. 2019.

UNIVERSIDADE DO ESTADO DA BAHIA (UNEB). Secretaria Especial de Relações Internacionais (SERINT). Relatório anual das ações da Secretaria de Relações Internacionais do ano de 2018. Salvador, 2018b. Disponível em: https://portal. uneb.br/serint/. Acesso em: 30 maio 2019.

UNIVERSIDADE DO ESTADO DA BAHIA (UNEB). Secretaria Especial de Relações Internacionais (SERINT). Relatório anual das ações de internacionalização por territórios da Bahia da Secretaria de Relações Internacionais do ano de 2018. Salvador, 2019. Disponível em: https:// portal.uneb.br/serint/. Acesso em: 01 ago. 2019.

Recebido em: 12/12/2018 Aprovado em: 10/05/2019 